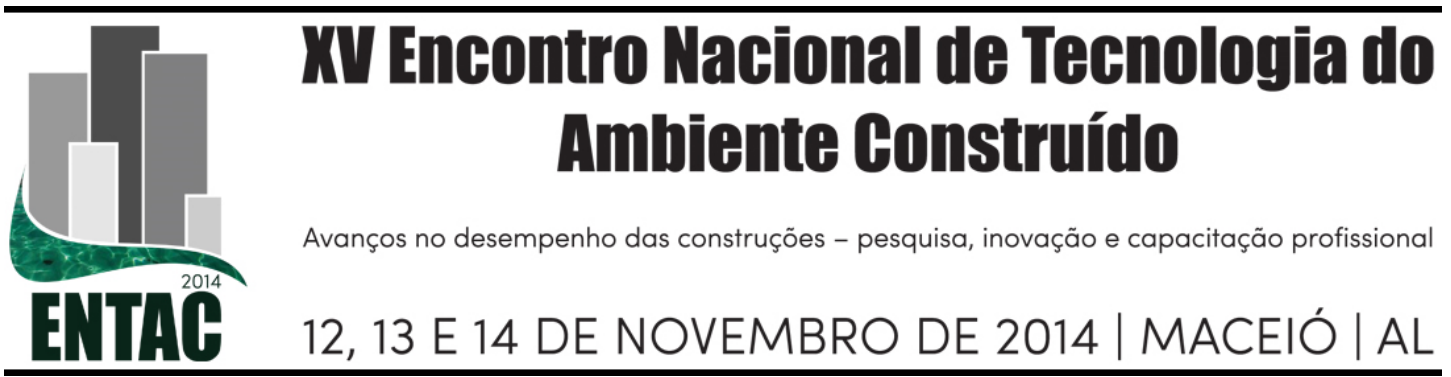

\title{
ANÁLISE DO POTENCIAL DE ECONOMIA BASEADO EM EDIFICAÇÕES COMERCIAIS ETIQUETADAS
}

\author{
SCALCO, Veridiana A. (1); FONSECA, Raphaela W. da (2); BECK, Elisa de O. \\ (3); PALLADINI, Gustavo D. (4); MAIA, Thalessa (5); ELI, Leticia (6);
}

LAMBERTS, Roberto (7)

(1) UFSC, LabEEE, e-mail: veridiana@labeee.ufsc.br (2) UFSC, LabEEE, e-mail: raphawf@gmail.com

(3) UFSC, LabEEE, e-mail: elisabeck@gmail.com (4) UFSC, LabEEE, e-mail: gustavopalla@gmail.com

(5) UFSC, LabEEE, e-mail: thalessa.maia@gmail.com (6) UFSC, LabEEE, e-mail: letícia.eli@hotmail.com (7) UFSC,LabEEE, e-mail: lamberts@labeee.ufsc.br

\begin{abstract}
RESUMO
Um dos questionamentos frequentes em relação aos Requisitos Técnicos da Qualidade para edifícios comerciais, de serviços e públicos (RTQ-C) refere-se ao qual seria o potencial de economia de energia de uma edificação para diferentes níveis de eficiência. Neste sentido, através deste artigo objetiva-se a avaliação exploratória do potencial de economia de energia considerando como base de dados tipologias de edificações etiquetadas. O programa S3e foi utilizado para quantificar o consumo de energia dos modelos de referência que representam os níveis A, B, C e D. Os resultados de comparação entre os consumos apontaram uma economia média de energia obtida entre os modelos de referência nível " $\mathrm{A}$ " $\mathrm{e}$ "D" de aproximadamente $26 \%$, variando entre $21 \%$ a $34 \%$ conforme a edificação e a zona bioclimática. A principal contribuição deste trabalho é a elucidação do potencial de economia de energia de uma edificação que considera o RTQ-C. Para a difusão e solidez da etiquetagem de eficiência energética de edificações é de fundamental importância que o setor da construção civil possa mensurar os benefícios de uma edificação com uma boa classificação de eficiência energética.
\end{abstract}

Palavras-chave: Etiquetagem de eficiência energética, RTQ-C, determinação da economia.

\begin{abstract}
One of the most frequently asked questions about the Brazilian Technical Regulation for Energy Efficiency Labeling of Commercial, Services and Public Buildings (RTQ-C) refers to what would be the building savings for different levels of efficiency. In this sense, this article aims to do an exploratory evaluation of energy savings considering as database the labeled buildings typologies. The S3e software quantifies the reference models energy consumption corresponding to the levels $A, B, C$ and $D$. The comparison among the consumptions results showed an average of energy savings about $25 \%$ between the reference models labeled as " $A$ " and " $D$ " and ranging from 20\% to 31\% depending on the building features and bioclimatic zone. The main contribution of this research is clarifying the buildings energy savings potential when considering RTQ-C. For the Regulation dissemination and solidity it is important the construction industry be able to measure the benefits of a building with a high energy efficiency rating.
\end{abstract}

Keywords: Energy efficiency labeling, $R T Q-C$, determination of the economy.

\section{INTRODUÇÃ̃O}

As edificações são responsáveis por $48,5 \%$ "do consumo energético no Brasil, sendo $24,2 \%$ referente às edificações residenciais, $16,3 \%$ às comerciais e $8 \%$ referente às 
edificações públicas (BEN, 2013). Este quadro indica a necessidade de que medidas de conservação de energia aplicadas ao setor de edificações assumam elevada importância, somado ao fato de que a produção da indústria da construção civil no Brasil está acelerada. $\mathrm{O}$ aumento da eficiência energética em edificações comerciais novas é uma das opções mais econômicas de reduzir o consumo energético, o custo de operação da edificação e a pegada das emissões de carbono (KNEIFEL, 2011).

Dentre as iniciativas visando à difusão da eficiência energética em edificações está o desenvolvimento de códigos, normas e certificações que tem por objetivo melhorar o desempenho energético das mesmas. Neste contexto, no Brasil, foi desenvolvido o programa Brasileiro de Etiquetagem de Edificações. O programa teve início com a promulgação da Lei $\mathrm{n}^{\circ}$ 10.295, de 17 de outubro de 2001 (BRASIL, 2001a), conhecida como Lei da Eficiência Energética. Esta lei dispõe sobre a Política Nacional de Conservação e Uso Racional de Energia e visa desenvolver, difundir e estimular a eficiência Energética no País. Regulamentada pelo Decreto no 4.059 , de 19 de dezembro de 2001 (BRASIL, 2001b) determinou que máquinas e aparelhos consumidores de energia fabricados ou comercializados no país, bem como as edificações construídas deveriam respeitar níveis máximos de consumo de energia, ou mínimos de eficiência energética, estabelecidos com base em indicadores técnicos e regulamentação específica.

A etiquetagem de edificações possui dois regulamentos, um para edificações comerciais, de serviços e públicas e um para residenciais que avaliam a edificação segundo uma escala de A (mais eficiente) a $\mathrm{E}$ (menos eficiente). O Regulamento para edificações comerciais, de serviços e públicas (BRASIL, 2010), escopo desta pesquisa, objetiva a etiquetagem destas edificações através da avaliação de três sistemas da edificação: a envoltória, sistema de iluminação e condicionamento de ar, além de possíveis bonificações.

Apesar do Regulamento estar em vigor desde 2009, não há nenhuma investigação acerca de quanto uma edificação economiza em relação ao estoque construído no país. Como este estoque não foi catalogado, uma das alternativas para preencher esta lacuna, seria avaliar o quanto uma edificação nível "A" economiza em relação à mesma edificação com níveis de eficiência menores, ou seja, com características que reduzam o seu desempenho (exemplo: envoltória com maior quantidade de vidros, iluminação e condicionamento de ar menos eficientes, etc). Para tanto, recorreu-se à base de dados de edificações etiquetadas fornecida pela Eletrobras. Com as informações constantes na base e o levantamento da volumetria através do programa Google Earth, utilizou-se o programa S3e para efetuar as simulações termo-energéticas das edificações. Como dados de saída, obteve-se o consumo da edificação real e o consumo para cada nível de eficiência (modelos de referência). Ao final foram obtidos os percentuais de economia entre um nível e outro para diferentes edificações situadas em diferentes climas do país.

\section{FUNDAMENTAÇÃO}

Cada vez mais, medidas governamentais no Brasil e em outros países do mundo vêm fomentando mudanças em setores de produção dirigidos à construção civil, indicando novos padrões de desempenho em prol de edificações energeticamente mais eficientes. As regulamentações no setor da construção civil têm um papel fundamental na redução do consumo de energia, classificando em níveis de eficiência desde a sua envoltória até os sistemas e equipamentos utilizados para seu pleno funcionamento. 
A implementação de parâmetros de classificação para as edificações, de acordo com o seu desempenho energético, vem sendo pesquisada em diversas instituições do mundo. Neste sentido, a verificação do potencial de economia através da melhoria substancial do desempenho das edificações assume um papel de grande importância.

Lee (2012) fez uma comparação entre cinco processos de avaliação: BREEAM, (Environmental Assessment Method), LEED (Leadership in Energy and Environmental Design), nos Estados Unidos, CASBEE (Comprehensive Assessment Scheme for Built Environment Efficiency), no Japão, BEAM Plus (Building Environmental Assessment Method Plus), em Hong Kong e ESGB (Evaluation Standard for Green Building), na China. De acordo com os relatórios USGBC (Turner et al., 2008 apud Lee, 2012), as edificações com certificação LEED são em média $28 \%$ mais eficientes do que a média do estoque construído nos Estados Unidos. No caso do BREEAM e BEAM Plus, Lee (2012) relata que as edificações certificadas são respectivamente $25 \%$ e $32 \%$ mais eficientes.

Lstiburek (2008) efetuou uma pesquisa semelhante a Lee (2012) onde afirma que edificações com certificação Leed Gold podem consumir até $25 \%$ menos do que a média de consumo das edificações sem certificação, com $27 \%$ de maior satisfação dos ocupantes e 19\% menor custo de manutenção.

Pan, Yin e Huang (2008) comparam os padrões das avaliações de China Public Building Energy Saving Design Standard com os padrões da ASHRAE Standard 90.1, visando analisar a economia de energia a partir de adoção de estratégias de eficiência energética a partir de parâmetros para: Transmitância de paredes e coberturas; Sistema de iluminação artificial e Sistema de condicionamento de ar, obtendo: $21 \%$ de economia comparada ao modelo base proposto pela ASHRAE Standard 90.1 e 27\% de economia para os padrões do código chinês.

Melo, Sorgato e Lamberts (2014) realizaram comparações entre os desempenhos dos diferentes níveis de classificação para dois modelos de edificações comerciais no Brasil localizadas em Brasília, Rio de Janeiro e Belém, em relação à ANSI/ASHRAE/Standard 90.1-2007 de padrão LEED, ao RTQ-C. Os resultados apontaram que o modelo de referência proposto pela ANSI/ASHRAE Standard 90.1-2007, teve equivalências em Brasília ao nível C de classificação pelo RTQ-C para a edificação 01 e nível B para a edificação 02. No Rio de Janeiro, ambas as edificações tiveram equivalência ao nível B e em Belém, ao nível A. Conforme observado nos resultados, o modelo de referência proposto pela ANSI/ASHRAE Standard 90.1-2007, teve equiparações aos modelos de referência para o RTQ-C que variaram de Nível C a A, de acordo com a localização nas diferentes cidades brasileiras e suas características climáticas.

A constatação do trabalho realizado por Melo, Sorgato e Lamberts (2014) sugere que há maior exigência para a obtenção de Nível A (mais eficiente) dentro da escala de classificação das edificações comerciais no Brasil através do RTQ-C em relação aos padrões da ANSI/ASHRAE Standard 90.1-2007. Em igual direção, os padrões do código chinês também tiveram resultados mais incisivos na redução de consumo em comparação com a ANSI/ASHRAE Standard 90.1-2007, mostrando-se, portanto, mais restritivo do que este.

Com relação às pesquisas citadas anteriormente, nota-se que regulamentações apontadas promovem economia através da redução do consumo de energia em relação aos estoques de edificações construídas até o momento levantadas. Apesar de não haver um levantamento do parque edificado brasileiro, a certificação do RTQ-C determina limites para utilização de parâmetros arquitetônicos (envoltória) e de sistemas (iluminação e 
condicionamento de ar) que visam à eficiência energética e, como consequência, geram economia.

\section{MÉTODO}

O conteúdo do presente artigo refere-se à avaliação dos consumos de energia entre os níveis de classificação do RTQ-C, utilizando modelos de referência representados pelos níveis $\mathrm{A}, \mathrm{B}, \mathrm{C}$ e $\mathrm{D}$, tendo em vista que o parque edificado do país não se encontra catalogado.

O método adotado foi separado em duas etapas: o levantamento das edificações etiquetadas e definição das tipologias das edificações e modelagem e simulação do consumo energético das tipologias das edificações.

\subsection{Tipologias de edificações}

Utilizou-se a base de dados das edificações etiquetadas pelo método prescritivo até o momento da pesquisa, que se constituem da maioria dos casos. A relação das edificações etiquetadas adotada foi obtida no sítio do Inmetro (INMETRO, 2013).

A tabela consultada em abril de 2013 apresentava 44 etiquetas de projeto, correspondentes a 36 edificações. Desta relação, somente 35 edifícios foram simulados; um deles foi desconsiderado por não possuir equivalência em termos de forma no programa S3e. Algumas características das edificações foram dispostas na tabela 1.

Tabela 1 - Características das edificações analisadas (adaptado de INMETRO, 2013)

\begin{tabular}{c|c|c|c|c|c|c|c|c}
\hline Ed. & ZB & Uso & $\begin{array}{c}\text { Área total } \\
{\left[\mathbf{m}^{2}\right]}\end{array}$ & $\begin{array}{c}\text { Número de } \\
\text { pavimentos }\end{array}$ & $\begin{array}{c}\mathbf{P A F}_{\mathbf{t}} \\
{\left[\mathbf{\%}^{\mathbf{t}}\right]}\end{array}$ & $\begin{array}{c}\mathbf{F S} \\
{[-]}\end{array}$ & $\begin{array}{c}\text { AVS } \\
{\left[{ }^{\mathbf{}}\right]}\end{array}$ & $\begin{array}{c}\text { AHS } \\
{\left[{ }^{\circ}\right]}\end{array}$ \\
\hline 1 & 2 & educação & 538,51 & 3 & 12 & 0,29 & 19,33 & 6,61 \\
\hline 2 & 8 & comercial/serviço & $59.765,10$ & 3 & 40 & 0,39 & 15,96 & 22,43 \\
\hline 3 & 3 & escritório & $3.336,24$ & 12 & 14 & 0,43 & 3,84 & 15,13 \\
\hline 4 & 3 & escritório & $5.072,61$ & 15 & 29 & 0,42 & 2,59 & 0,05 \\
\hline 5 & 3 & escritório & $4.018,94$ & 10 & 18 & 0,53 & 10,83 & 14,19 \\
\hline 6 & 3 & escritório & $16.452,16$ & 28 & 30 & 0,33 & 2,36 & 3,55 \\
\hline 7 & 3 & escritório & $27.569,23$ & 25 & 42 & 0,29 & 14,80 & 3,77 \\
\hline 8 & 3 & educação & $2.332,74$ & 4 & 11 & 0,87 & 14,27 & 0 \\
\hline 9 & 3 & educação & 815 & 2 & 16 & 0,84 & 21,02 & 12,57 \\
\hline 10 & 3 & educação & 915,97 & 2 & 33 & 0,86 & 33 & 1,41 \\
\hline 11 & 3 & escritório & $15.452,87$ & 15 & 14 & 0,43 & 9,88 & 12,07 \\
\hline 12 & 8 & comercial/serviço & $1.354,76$ & 6 & 17 & 0,44 & 5,71 & 5,02 \\
\hline 13 & 3 & educação & $4.651,95$ & 4 & 12 & 0,50 & 0 & 0 \\
\hline 14 & 3 & educação & $9.401,75$ & 5 & 19 & 0,87 & 6,43 & 15,54 \\
\hline 15 & 2 & escritório & $1.531,68$ & 3 & 14 & 0,87 & 39,15 & 18,06 \\
\hline 16 & 2 & escritório & 545,51 & 2 & 11 & 0,74 & 28,76 & 8,99 \\
\hline 17 & 3 & hotel & $3.336,24$ & 12 & 14 & 0,43 & 3,84 & 15,13 \\
\hline 18 & 8 & banco & 695,49 & 2 & 10 & 0,86 & 0 & 0 \\
\hline 19 & 2 & escritório & $1.531,68$ & 3 & 14 & 0,87 & 39,15 & 18,06 \\
\hline 20 & 3 & escritório & $4.282,06$ & 4 & 20 & 0,58 & 12,55 & 7,49 \\
\hline 21 & 3 & educação & $1.817,05$ & 2 & 15 & 0,87 & 12,78 & 2,02 \\
\hline 22 & 3 & escritório & $13.549,87$ & 4 & 18 & 0,43 & 11,87 & 26,17 \\
\hline 23 & 3 & banco & $1.146,56$ & 2 & 18 & 0,58 & 11,67 & 1,40 \\
\hline 24 & 3 & educação & $3.578,80$ & 2 & 17 & 0,87 & 19,36 & 26,15 \\
\hline & & & & & & & \\
\hline
\end{tabular}




\begin{tabular}{c|c|c|c|c|c|c|c|c}
\hline 25 & 3 & escritório & $4.100,65$ & 4 & 18 & 0,57 & 18,39 & 5,03 \\
\hline 26 & 1 & banco & 916,28 & 2 & 15 & 0,87 & 15,38 & 5,37 \\
\hline 27 & 8 & banco & $16.809,06$ & 8 & 11 & 0,64 & 0,03 & 0 \\
\hline 28 & 3 & escritório & $3.645,98$ & 4 & 16 & 0,57 & 14,47 & 7,43 \\
\hline 29 & 8 & hotel & $7.810,91$ & 10 & 26 & 0,40 & 11,83 & 0,66 \\
\hline 30 & 4 & escritório & $4.931,52$ & 6 & 22 & 0,36 & 36,49 & 11,56 \\
\hline 31 & 3 & banco & $1.708,30$ & 2 & 10 & 0,79 & 14,40 & 7,12 \\
\hline 32 & 3 & escritório & $5.784,36$ & 2 & 6 & 0,18 & 0,33 & 0,80 \\
\hline 33 & 4 & escritório & $21.418,80$ & 5 & 10 & 0,87 & 5,37 & 25,31 \\
\hline 34 & 8 & escritório & $11.153,40$ & 10 & 27 & 0,52 & 6,38 & 7,66 \\
\hline 35 & 4 & banco & 486,58 & 1 & 10 & 0,87 & 27,32 & 12,70 \\
\hline
\end{tabular}

A maior parte dos edifícios etiquetados pelo método prescritivo até o momento da pesquisa tratavam se de edificações destinadas a escritórios e à educação, além de não possuírem altura elevada.

\subsection{Modelagem e simulações}

Para a realização da modelagem e simulações das edificações utilizou-se o programa S3e desenvolvido no Laboratório de Eficiência Energética - LabEEE da Universidade Federal de Santa Catarina. Este programa constitui-se de uma interface para o software de domínio público EnergyPlus (versão 6.0), que é desenvolvido pelo Departamento de Energia dos Estados Unidos em cooperação com diversos centros de pesquisa. Este programa realiza, através do método do balanço térmico, o cálculo da carga térmica em cada zona térmica em intervalos de 15 minutos ou até menos conforme definido pelo usuário. Além disso, considera as cargas internas de iluminação, equipamentos e ocupação, as características construtivas da edificação (dimensões, espessuras e propriedades dos materiais), bem como as características climáticas do local da edificação (arquivo climático com registro horário de dados de temperatura de bulbo seco, temperatura de bulbo úmido, velocidade e direção do vento, etc., para o período de um ano, ou seja, 8.760 horas).

Para a inclusão das edificações no S3e foram utilizadas informações da base de dados das edificações etiquetadas fornecida pela Eletrobras, tais como dimensões básicas, localização, orientação, características construtivas e dos sistemas de iluminação e condicionamento de ar. Foram necessárias algumas simplificações, principalmente relativas à envoltória em função das geometrias disponíveis no programa.

As aproximações das geometrias foram feitas a partir da área construída prevista na base de dados. Como na planilha não constam informações sobre a geometria utilizouse os programas Google Earth, buscando-se aproximar-se o polígono ao máximo da área prevista na base de dados.

Para as edificações não construídas até o momento do levantamento, foram feitas aproximações da geometria em retângulos a partir da área prevista na base de dados. A escolha do uso dos retângulos, é justificada a partir da definição de que por ser não ter conhecimento da geometria original, deve-se utilizar uma geometria que não privilegie o auto sombreamento. Portanto, definiu-se também de maneira conservadora a orientação dessas edificações, considerando-se o maior lado do perímetro como sendo a fachada Oeste.

Outras considerações específicas também foram adotadas segundo a disponibilidade de informações e características específicas de cada edificação. Os edifícios foram 
simulados com base nas informações reais, portanto os níveis de classificação de eficiência energética encontrados na simulação foram similares aos previstos na base de dados.

As informações consultadas na base de dados foram: A avaliação geral (com valores das áreas de cada edifício e número de pavimentos) a análise da envoltória (valores de transmitância, absortância, PAFt, FS, AHS, AVS e equivalente numérico...). A análise do sistema de iluminação (valores de DPI e equivalente numérico do sistema). A análise do sistema de ar condicionado (COP e Equivalente numérico do sistema). Bonificações não foram avaliadas.

Para a escolha dos materiais, foi necessário atender a biblioteca disponível do S3e, e utilizando-se a base com as informações de transmitância térmica, absortância e FS, foi possível escolher materiais de fechamento e cobertura, assim como os vidros.

Para definir os sistemas de iluminação de cada edificação, utilizou-se os valores de DPI e equivalente numérico do sistema. $\mathrm{O}$ uso da edificação foi utilizado como parâmetro de entrada e adaptado quando necessário de forma a se adequar a algum dos usos tipos padrão do S3E, como: Banco, Escola ou Escritório. O S3e adota o método da área, logo todas as edificações foram avaliadas segundo este método.

Para o sistema de ar condicionado utilizou-se apenas a classificação geral do sistema de acordo com a base de dados. Como forma de simplificar a análise definiu-se o uso de split como padrão, adotando COP referente à mesma classificação do equipamento original.

Para as edificações em que apenas a envoltória foi etiquetada, por não ser possível simular-se apenas a envoltória no S3e, considerou-se que os sistemas de iluminação e condicionamento de ar adotados teriam eficiência mediana com equivalência à classificação C.

\section{RESULTADOS E DISCUSSÃO}

Os resultados das simulações foram analisados previamente de duas formas: determinou-se a economia de consumo que os demais níveis teriam em relação ao nível A e a economia de consumo de nível a nível (A em relação ao nível $\mathrm{B}$, nível $\mathrm{B}$ em relação ao nível $\mathrm{C}$ e nível $\mathrm{C}$ em relação ao nível $\mathrm{D}$ ). Em seguida, realizou-se outra investigação com apenas algumas edificações da amostra inicial para verificar a influência da Zona Bioclimática nas economias.

A economia de energia do nível D para o nível A variou entre $31,57 \%$ para a edificação 1, localizada em Pelotas, na zona bioclimática 2 até $20,37 \%$ para a edificação 34 , localizada em Brasília, na zona bioclimática 4. Sendo que a média de economia das edificações foi de 24,98\% (figura 1).

Já a economia de energia do nível C para o nível A variou entre 23,99\%, também para a edificação 1 e 14,04\% novamente para a edificação 34 . Sendo que a média de economia entre os níveis foi de 17,46\% (figura 1).

A economia do nível B para o nível A, diferentemente dos casos anteriores, teve seus casos extremos encontrados em outras edificações. Neste caso a economia variou entre $11,77 \%$ para o edifício 2, localizado na cidade de Salvador, zona bioclimática 8 e 6,68\% para a edificação 25, localizada em Curitiba, na zona bioclimática 1 (figura 1). Sendo que a média de economia entre os níveis foi de $9,12 \%$. 
Figura 1 - Economia em relação ao nível A para cada edificação

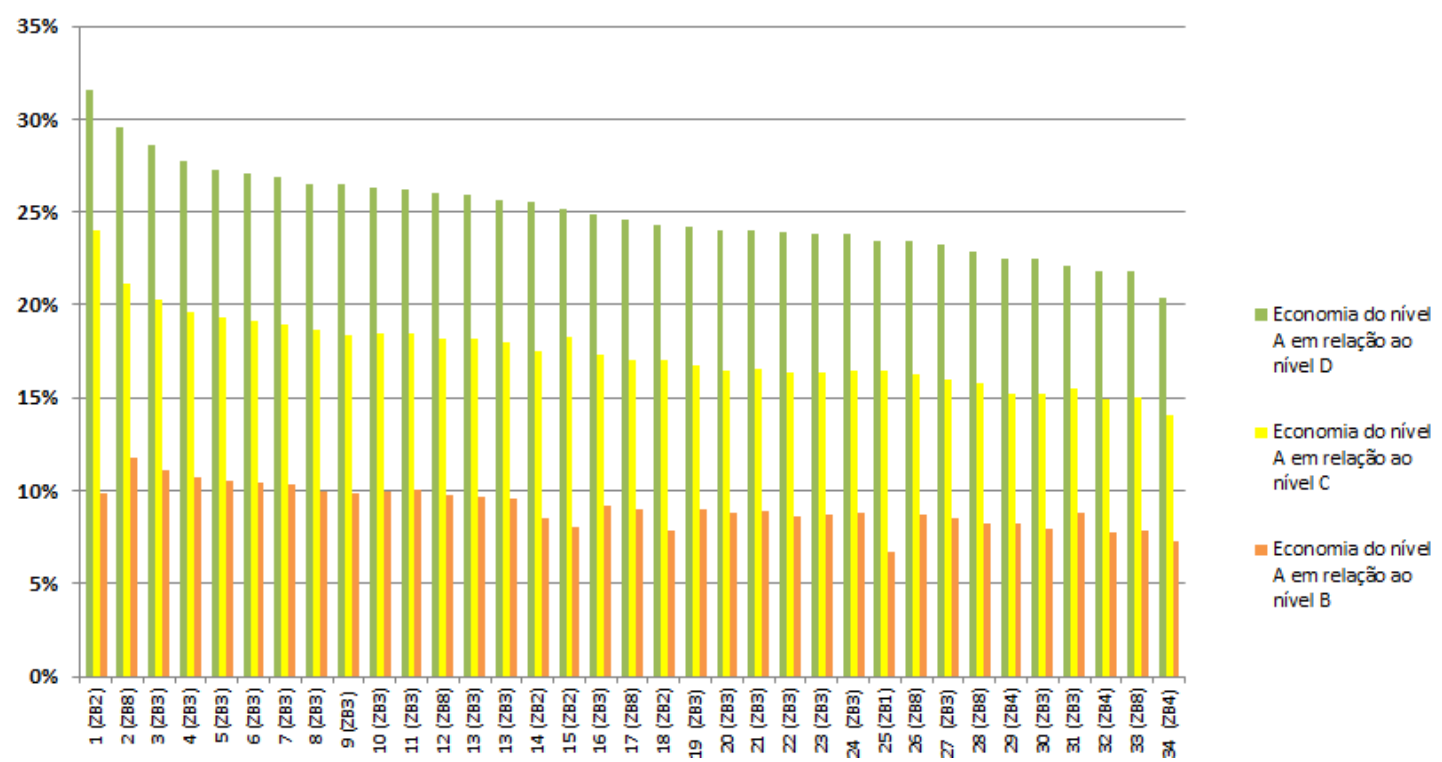

Analisando a economia entre níveis (figura 2), do nível $D$ para o A nota-se que a maior economia é verificada nas edificações da ZB2, seguida da ZB8, ZB3, ZB1 e ZB4. Já analisando a economia de um nível para outro (nível $\mathrm{A}$ em relação ao nível $\mathrm{B}$, nível $\mathrm{B}$ em relação ao nível $\mathrm{C}$ e nível $\mathrm{C}$ em relação ao nível $\mathrm{D}$ ) pode-se notar que a economia varia muito para a ZB1, sendo menor para a economia de A para B, seguindo da economia de $\mathrm{C}$ para $\mathrm{D}$ e com a maior economia na variação do nível de $\mathrm{B}$ para $\mathrm{C}$. $\mathrm{A}$ ZB2 também apresenta variações conforme a ZB1. Já nos casos das demais zonas bioclimáticas, a diferença entre um nível e outro se mostra bastante aproximada.

$\mathrm{O}$ percentual de economia do nível $\mathrm{D}$ para o nível $\mathrm{C}$ foi o que apresentou menos diferença entre as diferentes zonas bioclimáticas (figura 3). Analisando separadamente as zonas 1 e 2, que apresentaram uma variação diferente das demais zonas, a zona 2 apresenta potencial de economia maior que a zona 1 para os três casos. Já as zonas 3, 4 e 8 apresentam o mesmo padrão para os três níveis, sendo que a ZB3 apresenta o maior potencial de economia, seguida pela ZB8 e então pela ZB4.

Figura 2 - Economia de um nível em relação ao outro.

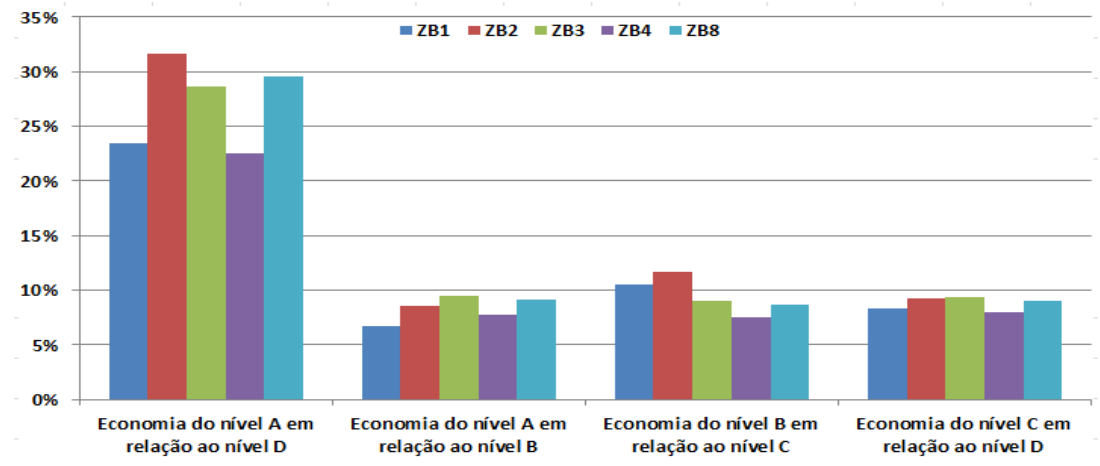

O resultado de maior variação para as ZB1 e ZB2 entre os níveis pode ser visto com maior clareza quando as economias por nível são agrupadas por zona, Figura 3. Neste 
caso fica clara a diferença entre o padrão de economia possível entre níveis das zonas bioclimáticas 1 e 2 e as demais.

Figura 3 - Economia de um nível em relação ao outro agrupado por zonas.

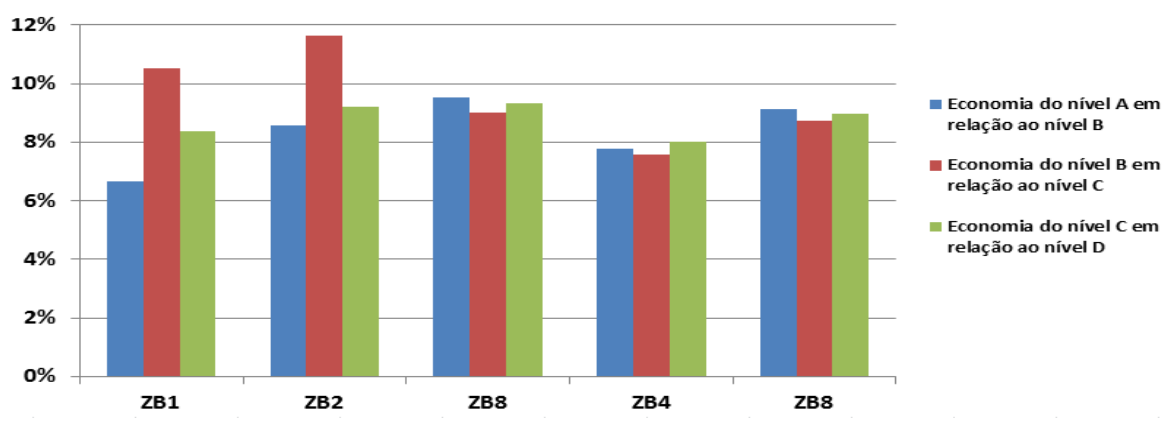

A fim de se investigar a influência da região onde se encontra a edificação, foram escolhidos aleatoriamente seis edifícios, sendo um de cada zona bioclimática, para uma análise do percentual de economia de um nível de classificação para outro, caso as mesmas edificações fossem construídas em outras Zonas Bioclimáticas. Para isso, as edificações da ZB1 (25) e ZB2 (14) foram simuladas na ZB8 e as das ZB3 (20 e 31), ZB4 (29) e ZB8 (17) na ZB1, Figura 4. Foram escolhidos dois arquivos da ZB3, visto que era a zona com maior número de empreendimentos. Visando certificar-se que a diferenciação não vinha do arquivo climático da cidade de Curitiba utilizado para representar a ZB1, a edificação 17 foi simulada com o arquivo climático de Campos do Jordão, também ZB1.

Figura 4 - Edifícios simulados em outras Zonas Bioclimáticas.

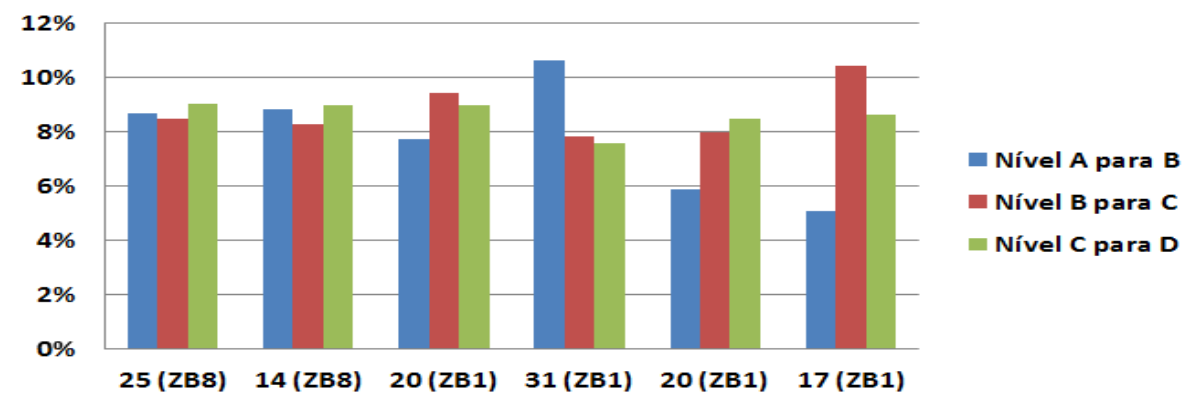

Com base nos resultados apresentados na Figura 4, pode-se confirmar a variação da influência da zona bioclimática (arquivos climáticos do tipo EPW compilados pelo Prof. Maurício Roriz adotados para a simulação), em especial para as ZB1 e ZB2. Visto que quando as edificações, originalmente localizadas nestas zonas, foram simuladas para ZB8 a diferença entre o percentual de economia de um nível para o outro passou a ser praticamente equivalente. Por outro lado, quando as edificações originalmente das zonas ZB3, ZB4 e ZB8 foram simuladas com arquivos climáticos da ZB1 a diferença de economia entre os níveis se acentuou. Entretanto, é importante notar que as edificações 20 e 17 não mantiveram a ordem de magnitude de percentual de economia, que as edificações das zonas ZB1 e ZB2 apresentaram no gráfico da Figura 4. 


\section{CONSIDERAÇÕES FINAIS}

Como principal contribuição deste trabalho pode-se destacar a mensuração do potencial de conservação de energia ao investir-se em uma edificação que almeje um melhor desempenho energético. Os resultados de comparação entre os consumos apontaram uma economia média de energia obtida entre os modelos de referência nível " $A$ " e " $D$ " de aproximadamente $26 \%$, variando entre $21 \%$ a $34 \%$ conforme a edificação e a zona bioclimática.

A informação de quanto uma edificação economiza em média ao mudar de um nível para o outro em um sistema de avaliação de eficiência energética permite uma análise da viabilidade econômica da adoção de determinadas decisões de projeto que promovam conservação de energia conforme o custo-benefício da estratégia adotada. As economias verificadas foram importantes, considerando que as edificações nível $\mathrm{D}$, quando alteradas visando o nível A poderiam alcançar pelo menos $20 \%$ de economia de energia.

Outra consideração importante foi a constatação de que nem sempre existe uma linearidade na economia verificada entre níveis (nível A em relação ao nível $\mathrm{B}$, nível $\mathrm{B}$ em relação ao nível $\mathrm{C}$ e nível $\mathrm{C}$ em relação ao nível $\mathrm{D})$. Ao investigar as seis edificações alterando-se a zona bioclimática, o comportamento esperado para edificações anteriormente simulados na Zona 1 e 2 foi confirmado; entretanto, para as edificações das demais Zonas simuladas não foi possível verificar um padrão. Este resultado aponta para uma importante investigação futura envolvendo análises, como, por exemplo, em relação à tipologia arquitetônica das edificações.

Por fim, cabe ressaltar que estudos desta natureza contribuem para a difusão de políticas públicas que possibilitem a conscientização e informação do consumidor além do comprometimento do setor da construção civil. Para evitar os efeitos de medidas emergenciais para o racionamento de energia, a consolidação das políticas públicas de eficiência energética de caráter preventivo torna-se essencial e mensuração de seu potencial de extrema importância.

\section{AGRADECIMENTOS}

À Eletrobras pelo financiamento da pesquisa.

\section{REFERÊNCIAS}

ASHRAE - AMERICAN SOCIETY OF HEATING, REFRIGERATING AND AIR CONDITIONING ENGINEERS. Energy Standard for Buildings Except Low-Rise Residential Buildings. ASHRAE Standard 90.1-1989. American Society of Heating, Refrigerating and Air-Conditioning Engineers. Atlanta, 1989.

BEN. Balanço Energético Nacional. 2013. Disponível em: < https://ben.epe.gov.br/downloads/Relatorio_Final_BEN_2013.pdf $>$. Acessado em: 18 ago. 2013.

BRASIL. Lei no 10.295, de 17 de outubro de 2001. Dispõe sobre a Política Nacional de Conservação e Uso Racional de Energia. Lex: Diário Oficial da União, Brasília, 2001a. Disponível em: www.inmetro.gov.br/qualidade/lei10295.pdf. Acesso em: 17 mar. 2013 
Decreto no 4.059, de 19 de dezembro de 2001. Regulamenta a Lei no 10.295, de 17 de outubro de 2001, que dispõe sobre a Política Nacional de Conservação e Uso Racional de Energia, e dá outras providências. Lex: Diário Oficial da União, Brasília, 2001b. Disponível em: <www.mme.gov.br/ministerio/legislacao/decretos/Decreto\%20n\%204.0592001.html>. Acesso em: 17 mar. 2013

Ministério do desenvolvimento, indústria e comércio exterior. Instituto Nacional de Metrologia, Normalização e Qualidade Industrial - INMETRO. Portaria $\mathbf{n}^{\mathbf{0}}$ 372, de 17 de setembro de 2010. Requisitos Técnicos da Qualidade para o Nível de Eficiência Energética de Edifícios Comerciais, de Serviços e Públicos (RTQ-C) (2010). Disponível em: $<$ http://www.inmetro.gov.br/consumidor/produtosPBE/EdificiosComerciais.asp $>$. Acesso em: 17 mar. 2013

EPE - Empresa de Pesquisa Energética. Plano Nacional de Energia - 2030. 2007. Disponível em: <http://www.epe.gov.br/PNE/20080111_1.pdf >. Acessado em: 02 mai. 2014.

MINISTÉRIO DE MINAS E ENERGIA. Plano Nacional de Eficiência Energética. Premissas e diretrizes básicas. Disponível em: $<$ http://www.mme.gov.br/mme/galerias/arquivos/PlanoNacEfiEnergetica.pdf $>$. Acessado em: 02 mai. 2014.

INMETRO. Tabelas de eficiência de edificações comerciais, de serviço e públicas. Disponível em: <http://www.inmetro.gov.br/consumidor/pbe/tabelas-comerciais.pdf $>$. Acessado em: 01 abr. 2013.

KNEIFEL, J. Beyond the code: Energy, carbon, and cost savings using conventional technologies. Energy and Buildings, v. 43, p. 951-959, 2011. Disponível em: $<$ http://www.sciencedirect.com/science/article/pii/S0378778811005706>. Acesso em: 5 mai. 2014.

LEE, W. L. Benchmarking energy use of building environmental assessment schemes. Energy and Buildings, v. 45, p. 326-334, 2012. Disponível em: $<$ http://www.sciencedirect.com/science/article/pii/S0378778811005706>. Acesso em: 5 mai. 2014.

LSTIBUREK, J. W. Why green can be wash. ASHRAE Journal, Atlanta, p.28-36, novembro de 2008. Disponível em: <http://www.pinp.org/pdf/ACF222B.pdf>. Acesso em: 9 mai. 2014.

MELO, A. P.; SORGATO, M. J.; LAMBERTS, R. Building energy performance assessment: Comparison between ASHRAE standard 90.1 and Brazilian regulation. Energy and Buildings, v. 70, p. 372-383, 2014. Elsevier B.V. Disponível em: $<$ http://linkinghub.elsevier.com/retrieve/pii/S0378778813007974>. Acesso em: 6 mai. 2014.

NEWSHAM, G. R.; MANCINI, S.; BIRT, B. J. Do LEED-certified buildings save energy? Yes, but... Energy and Buildings, v. 41, n. 8, p.897-905, 2009. Disponível em: <http://linkinghub.elsevier.com/retrieve/pii/S0378778809000693>. Acesso em: 5 mai. 2014.

PAN, Y.; YIN, R.; HUANG, Z. Energy modeling of two office buildings with data center for green building design. Energy and Buildings, v. 40, n. 7, p. 1145-1152, 2008. Disponível em: $<\mathrm{http}: / /$ www.sciencedirect.com/science/article/pii/S037877880700240X $>$. Acesso em: 9 mai. 2014. 